\title{
Serum levels of cytokines and C-reactive protein in acute ischemic stroke patients, and their relationship to stroke lateralization, type, and infarct volume
}

\author{
Heidi Ormstad • Hans Christian Dalsbotten Aass • \\ Niels Lund-Sørensen • Karl-Friedrich Amthor • \\ Leif Sandvik
}

Received: 27 August 2010/Revised: 31 January 2011/Accepted: 8 March 2011/Published online: 20 March 2011 (C) The Author(s) 2011. This article is published with open access at Springerlink.com

\begin{abstract}
There is increasing evidence that inflammation plays an important role in the progression of acute ischemic stroke (AIS). The primary aims of this study were to examine the serum levels of 13 cytokines, C-reactive protein (CRP), glucose, and hemoglobin in AIS patients, and their relationship to stroke lateralization, type, and infarct volume. Forty-five patients with AIS were evaluated. Blood samples were taken within $72 \mathrm{~h}$, and volumetric analyses performed within 1-7 days after AIS onset. Cytokines were measured in serum from all patients and from 40 control subjects using Luminex Bio-Plex XMap technology. The levels of interleukin (IL)-1ra $(p<0.001)$, IL-6 $(p<0.001)$, IL-8 $(p<0.001)$, IL-9 $(p=0.038)$, IL$10(p=0.001), \mathrm{IL}-12(p=0.001), \mathrm{IL}-18(p<0.001)$, and
\end{abstract}

H. Ormstad ( $\square)$

Vestre Viken Hospital Trust,

Bærum sykehus, Postbox 83, 1309 Rud, Norway

e-mail: heidi.ormstad@vestreviken.no

H. Ormstad

Department of Health Sciences, Buskerud University College,

Drammen, Norway

H. C. D. Aass

The R \& D Group, Department of Medical Biochemistry, Oslo University Hospital, Ullevål, Oslo, Norway

N. Lund-Sørensen

Department of Radiology, Vestre Viken Hospital Trust,

Buskerud, Norway

K.-F. Amthor

Department of Neurology, Vestre Viken Hospital Trust,

Buskerud, Norway

L. Sandvik

Section of Biostatistics, Oslo University Hospital,

Ullevål, Oslo, Norway
GRO- $\alpha$ (CXCL1) $(p=0.017)$ were significantly higher in the AIS patients than in the controls. The IL-8 level was significantly correlated with age in the patient group $(r=0.52, p<0.001)$. None of the variables were found to be associated with stroke lateralization. Infarct volume was significantly positively correlated with CRP level $(r=0.47, p=0.005)$. Patients with radiologically confirmed infarctions had significantly elevated serum levels of GRO- $\alpha(p=0.023)$. The cytokine profile of the AIS patients supports not only earlier findings of a proinflammatory response but also early activation of endogenous immunosuppressive mechanisms. Novel findings of this study are elevated serum levels of IL-9 and GRO- $\alpha$. Elevated GRO- $\alpha$ in AIS patients with radiologically confirmed infarctions suggests that GRO- $\alpha$ is specific for stroke of known etiology. Our results indicate that CRP plays an important role in the progression of cerebral tissue injury.

Keywords Acute ischemic stroke - Inflammation · Cytokines $\cdot$ Proinflammatory $\cdot$ Anti-inflammatory

\section{Background}

There is increasing evidence that inflammation plays an important role in acute ischemic stroke (AIS), indicating important interactions between the nervous and immune systems [1]. Cerebral ischemia induces a robust inflammatory reaction that involves several cell types. Many recent studies have focused on the inflammatory reaction after the ischemic episode, identifying the roles of important inflammatory signaling molecules, particularly cytokines [2]. Cytokines are up-regulated in the brain after stroke, and are expressed not only in immunological cells but also in glial cells and neurons [3]. 
The most studied cytokines related to stroke are interleukin (IL)-1 $\beta$, IL-6, IL-10, and tumor necrosis factor- $\alpha$ (TNF$\alpha$ ). The proinflammatory cytokines TNF- $\alpha$, IL- $1 \beta$, and IL-6 are secreted in the ischemic region by activated immune cells, which drive the inflammatory process and accelerate additional inflammatory processes by inducing the expression of inflammatory molecules. These molecules recruit more circulating leukocytes, which infiltrate the ischemic region and lead to further loss of neuronal cells and brain tissue, thereby possibly enlarging the cerebral infarct area $[4,5]$. Whether postischemic inflammatory responses are deleterious or beneficial to brain recovery is presently a matter of debate [6]. Several studies have examined whether the inflammatory response following AIS is related to infarct volume [7-14] and stroke subtype [15]. The results are inconsistent, thus the roles of the cytokines involved are still unclear.

Various known cytokines have been studied individually, but no study has evaluated numerous different cytokines in a single patient group using one methodology. The aim of this study was to measure the serum levels of 13 cytokines in patients with AIS to improve the understanding of the complex interplay between the pro- and anti-inflammatory cytokines involved. We also examined the relation of serum levels of hemoglobin, C-reactive protein (CRP), and glucose to stroke lateralization, diagnostic subtype, and infarct volume.

\section{Methods}

\section{Patients}

The cohort comprised 45 patients included in a longitudinal study of first-ever stroke patients admitted to Buskerud Hospital, a regional hospital in Norway. The recruiting procedure is described in detail elsewhere [16]. In short, the inclusion criteria were clinical presentation of first-ever stroke, age 18 years or older, and exhibiting sufficient cognitive functioning to participate. Stroke was defined as the presence of rapidly developing focal neurological signs or symptoms of vascular origin that persisted for $>24 \mathrm{~h}$. The exclusion criteria were no serum samples collected, uncertain diagnosis of AIS, presence of cancer, receiving thrombolysis therapy, and uncertain symptom onset.

\section{Clinical and instrumental evaluation}

A general medical history was collected, and physical and neurological examinations, standard laboratory tests, 12-lead ECG, and cerebral CT were performed in all patients on admission. Patients without clear radiological findings on admission, but with persistent clinical symptoms indicative of AIS after 2-4 days were submitted to a secondary CT or
MRI scan. The type of AIS was classified according to the Trial of Org 10172 in Acute Stroke Treatment (TOAST) classification [17]: cardioembolic infarct (CEI), large-artery atherosclerosis (LAAS), lacunar infarct (LAC), stroke of undetermined etiology (UDE), and stroke of other determined etiology. Lateralization of the stroke was determined by clinical findings and imaging results, or on a clinical basis only in patients without conclusive CT or MRI findings. Location of the stroke, supra- or infratentorial respectively, was determined by radiological findings.

The functional disability of patients in the acute phase was measured using the Barthel Index-20 scale (BI-20) [18]. The BI-20 has proven to be the most reliable disability scale for stroke; it correlates strongly with the immediate poststroke condition [19].

Imaging and volumetric analysis

The imaging used for measurement of infarct volume was performed within 1-2 days, 3-5 days, and 7 days after stroke onset for 11,22 , and one of the 34 patients, respectively. Infarct volumes were measured on either MRI (24/34 cases) or CT (10/34). On MRI, diffusion sequences were used in the axial plane, combined with sagittal T2 turbo spin-echo and/or coronal fluid-attenuated inversion recovery imaging. An onscreen measuring technique was used. On CT, measurements were made on axial slices in combination with thickness data.

Control subjects

Control serum samples were prepared by collecting blood from 40 healthy donors (The Bloodbank, Oslo University Hospital, Ullevål, Oslo, Norway) with an even female/male distribution. We achieved a biobank similar to that of the material collected from our stroke patients by selecting donors aged 50-70 years. None of the donors were using immunosuppressive medication.

\section{Blood collection and serum preparation}

Blood samples were taken at the same time point for all blood components measured; at <24, 24-48, and 48-72 h after stroke onset in 35,7 , and three of the 45 patients, respectively. For cytokine measurements blood was collected in 7.5-ml serum S-Monovette gel tubes (Sarstedt, Nümbrecht, Germany), and stored for 30-120 min at room temperature prior to centrifugation at $1,400 \times g$ for $12 \mathrm{~min}$. Serum samples were frozen at $-70^{\circ} \mathrm{C}$.

CRP, glucose, and hemoglobin measurements

Serum levels of CRP, glucose, and hemoglobin were all determined with clinically validated assays. Determination 
of CRP was performed using a standard latex immunoassay; CRP Vario (Abbott Diagnostics). Glucose was determined using Architect cSystems (Abbott Diagnostics). Finally, Hemoglobin was determined using Advia 120 Hematology system (Siemens Health Care Diagnostics).

\section{Cytokine measurement}

Cytokine levels were measured using a Luminex IS 100 instrument (Bio-Rad, Hercules, CA). Based on a screening of representative serum samples using the Bio-Plex human cytokine 27-plex assay (catalog no. 171A11127, Bio-Rad), the following custom plex was purchased to screen all samples: Bio-Plex Pro ${ }^{\mathrm{TM}}$ Human Cytokine Group I; IL-1 $\beta$, IL-1ra, IL-2, IL-4, IL-6, IL-8, IL-9, IL-10, IL-12, TNF- $\alpha$, and interferon- $\gamma($ IFN- $\gamma)$; Bio-Plex Pro ${ }^{\mathrm{TM}}$ Human Cytokine Group II; and GRO- $\alpha$ (CXCL1) and IL-18 (Bio-Rad). All samples were thawed on ice, vortexed, spun down at $14,000 \times g$ for $10 \mathrm{~min}$ at $4^{\circ} \mathrm{C}$, and then diluted at 1:4. Longitudinal controls were used to assess the interassay variation. The coefficient of variation for controls ranged from 9 to $19 \%$ on the exponential phase of the standard curve.

\section{Statistical analysis}

The two-tailed Mann-Whitney test was used to compare the median values of cytokine variables in two groups. The independent-samples $t$ test was used to compare means. The level of statistical significance was set at $p<0.05$. If more than $50 \%$ of the values of a cytokine variable were not detectable in at least one of the groups, the variable was dichotomized as detectable (yes/no) and analyzed using Pearson's Chi-square test.

Since the distributions of most of the cytokine variables were markedly skewed, the results are presented as medians and interquartile ranges. When age was found to be a confounder for a difference in cytokine variables between the groups, linear regression analysis was used to adjust for age. The Spearman correlation coefficient was used to quantify the association between two continuous variables. All statistical analyses were performed using the SPSS statistical package (version 15, SPSS, Chicago, IL).

\section{Results}

All clinical data of the AIS patients are presented in Table 1 . The gender distribution did not differ significantly between the AIS and control groups, but the mean age was significantly higher in the former (67.7 vs. 59.1 years, respectively; $p<0.001)$. Twenty-two patients had rightsided, 21 left-sided and 2 bilateral ischemic stroke. The infarct volume measured in the 34 patients with a radiologically confirmed infarction ranged from 0.5 to $140 \mathrm{~cm}^{3}$, with a median value of $2 \mathrm{~cm}^{3}(1,17)$.

Serum levels of cytokines in the AIS and control subjects are also presented in Table 1. The levels of the following cytokines were significantly higher in the AIS patients than in the controls: IL-1ra $(p<0.001)$, IL-6 ( $p<0.001)$, IL-8 $(p<0.001)$, IL-9 $(p=0.038)$, IL-10 $(p=0.001)$, IL-12 $(p=0.001)$, IL-18 $(p<0.001)$, and GRO- $\alpha(p=0.017)$. IL- 8 was significantly correlated with age in the patient group $(r=0.52, p<0.001)$, but not in the control group. The difference in IL- 8 between the groups remained significant after adjusting for age $(p<0.001)$.

To get an indication of the stability of the cytokines, secondary blood samples were taken from 33 of the patients, between 2 and 5 days after stroke onset. Comparing the acute-phase cytokine levels and these secondary cytokine levels revealed that the only cytokines that changed significantly were IL-18 and GRO- $\alpha$. The median level of IL-18 decreased from 1,820 to $1,630 \mu \mathrm{g} / \mathrm{ml}$ ( $p=0.011$ ), whilst that of GRO- $\alpha$ decreased from 1,207 to $868 \mu \mathrm{g} / \mathrm{ml}(p=0.006)$. This indicates that most of the investigated cytokines are relatively stable for many hours, or even days, after stroke onset. This is also supported by several previous studies, as discussed later.

The BI-20 score was significantly negatively correlated with the levels of IL-2 $(r=-0.354, p=0.02)$, IL-6 $(r=$ $-0.334, p=0.028)$, IL-12 ( $r=0.38, p=-0.012)$, and IFN- $\gamma(r=-0.37, p=0.014)$. No differences were found between left-sided and right-sided infractions for any of the immunological markers, hemoglobin, glucose, or BI-20 score. The group with infratentorial findings was too small $(n=4)$ to allow for detailed statistical analysis on location.

Infarct volume was significantly positively correlated with CRP level ( $r=0.47, p=0.005$ ). No correlation was found between infarct volume and any of the immunological markers, hemoglobin, glucose, or BI-20 score.

TOAST variables were dichotomized in radiologically confirmed infarctions (merged CEI, LAAS, and LAC) and radiologically unconfirmed infarctions (UDE); data presented in Table 2. Patients with radiologically confirmed infarctions had significantly elevated serum levels of GRO$\alpha(1,613$ vs. $888 \mu \mathrm{g} / \mathrm{ml}, p=0.023)$. This group also had significantly lower age (56 vs. 74 years, $p=0.037$ ) and significantly lower prevalence of coronary disease (9 vs. $36 \%), p=0.028)$. Age and presence of coronary disease was not correlated with GRO- $\alpha$; thus, the differences in serum level of GRO- $\alpha$ cannot be explained by the difference in these variables between the two groups. We did not find any differences between these two groups in regard to any of the other immunological markers, hemoglobin, glucose, or BI-20 score. 
Table 1 Clinical variables of the acute ischemic stroke (AIS) patients and cytokine serum levels of these and control subjects

\begin{tabular}{|c|c|c|c|}
\hline Characteristic & Stroke patients $(n=45)$ & Control subject $(n=40)$ & $p$ \\
\hline Male, $n(\%)$ & $27(60)$ & $20(50)$ & 0.14 \\
\hline Mean age, years $\pm \mathrm{SD}^{\mathrm{e}}$ & $67.7 \pm 11.8$ & $59.1 \pm 5.7$ & $<0.001$ \\
\hline Right-sided ischemic stroke, $n(\%)$ & $22(49 \%)$ & & \\
\hline Radiologically confirmed infarction, $n(\%)$ & $34(53 \%)$ & & \\
\hline Supratentorial infarction, $n$ (\% of 34 ) & $30(88 \%)$ & & \\
\hline \multicolumn{4}{|l|}{ TOAST } \\
\hline CEI & $5(11 \%)$ & & \\
\hline LAAS & $10(22 \%)$ & & \\
\hline LAAC & $19(42 \%)$ & & \\
\hline UDE & $11(24 \%)$ & & \\
\hline \multicolumn{4}{|l|}{ Medication } \\
\hline Prednisolone & $3(7 \%)$ & & \\
\hline NSAIDs & $3(7 \%)$ & & \\
\hline \multicolumn{4}{|l|}{ Co-morbidity } \\
\hline Hypertension & $28(62 \%)$ & & \\
\hline Atrial fibrillation & $6(13 \%)$ & & \\
\hline Coronary disease & $7(16 \%)$ & & \\
\hline Diabetes & $4(9 \%)$ & & \\
\hline Rheumatism & $2(4 \%)$ & & \\
\hline Psoriatic arthritis & $3(7 \%)$ & & \\
\hline Bechterew's disease & 1 & & \\
\hline Hyperthyroidism & 1 & & \\
\hline \multicolumn{4}{|l|}{ Mean values, $\pm \mathrm{SD}$} \\
\hline Hemoglobin (g/dl) & $14.3 \pm 1.3$ & & \\
\hline Glucose (mmol/l) & $7.0 \pm 2.3^{\mathbf{a}}$ & & \\
\hline \multicolumn{4}{|l|}{ Median values, interquartile range } \\
\hline BI-20 & $20(17,20)^{\mathbf{b}}$ & & \\
\hline Infarct volume $\left(\mathrm{cm}^{3}\right)$ & $2(1,17)$ & & \\
\hline $\mathrm{CRP}(\mathrm{mg} / \mathrm{l})$ & $3(2.0,6.5)$ & & \\
\hline \multicolumn{4}{|l|}{ Median values, interquartile range ${ }^{c}$} \\
\hline \multicolumn{4}{|l|}{ Cytokines } \\
\hline IL-1 ra $(\mu \mathrm{g} / \mathrm{ml})$ & $1,170(840,1,573)$ & $492(386,662)$ & $<0.001$ \\
\hline IL-8 ( $\mu \mathrm{g} / \mathrm{ml})$ & $200(123,251)$ & $98(73,130)$ & $<0.001$ \\
\hline IL-18 ( $\mu \mathrm{g} / \mathrm{ml})$ & $1,767(1,405,2,262)$ & $1,187(899,1,689)$ & $<0.001$ \\
\hline GRO- $\alpha$ & $1,493(431,1,821)$ & $691(483,1,351)$ & 0.017 \\
\hline \multicolumn{4}{|l|}{ Dichotomized values (\% detectable of total) ${ }^{\mathrm{d}}$} \\
\hline \multicolumn{4}{|l|}{ Cytokines } \\
\hline IL- $1 \beta$ & $10(22 \%)$ & $8(20 \%)$ & 0.80 \\
\hline IL-2 & $2(4 \%)$ & $1(3 \%)$ & 0.63 \\
\hline IL-4 & $9(22 \%)$ & $4(10 \%)$ & 0.19 \\
\hline IL-6 & $42(93 \%)$ & $15(38 \%)$ & $<0.001$ \\
\hline IL-9 & $18(41 \%)$ & $8(20 \%)$ & 0.038 \\
\hline IL-10 & $24(56 \%)$ & $8(21 \%)$ & 0.001 \\
\hline IL-12 & $24(57 \%)$ & $9(23 \%)$ & 0.001 \\
\hline IFN- $\gamma$ & $12(27 \%)$ & $8(20 \%)$ & 0.47 \\
\hline TNF- $\alpha$ & $27(60 \%)$ & $18(45 \%)$ & 0.17 \\
\hline
\end{tabular}

Significant findings $(p<0.05)$ are marked with bold-faced types

a One missing case

b Two missing cases

c Two-tailed Mann-Whitney test was used for comparison of the groups

${ }^{d}$ Pearson Chi-square test was used for comparison of the groups

e Independent sample t-test was used for comparison of the groups 
Table 2 Clinical variables and serum levels of cytokine in patients with and without radiologically confirmed infarctions

\begin{tabular}{|c|c|c|c|}
\hline Variable & $\begin{array}{l}\text { Patients with radiologically } \\
\text { confirmed infarctions (merged } \\
\text { CEI, LAAS and LAC) }(n=34)\end{array}$ & $\begin{array}{l}\text { Patients without radiologically } \\
\text { confirmed infarctions } \\
\text { (UDE) }(n=11)\end{array}$ & $p$ \\
\hline Male, $n(\%)$ & $20(74)$ & $7(64)$ & \\
\hline Mean age, years $\pm \operatorname{SD}^{c}$ & $65 \pm 12.2$ & $74.1 \pm 8.1$ & $\mathbf{0 . 0 3 7}$ \\
\hline Right-sided ischemic stroke, $n(\%)$ & $16(47 \%)$ & $6(55 \%)$ & 0.34 \\
\hline \multicolumn{4}{|l|}{ Medication } \\
\hline Prednisolone & $2(6 \%)$ & $1(9 \%)$ & \\
\hline NSAIDs & $3(9 \%)$ & None & \\
\hline \multicolumn{4}{|l|}{ Co-morbidity } \\
\hline Hypertension & $21(62 \%)$ & $7(63 \%)$ & 0.91 \\
\hline Atrial fibrillation & $5(15 \%)$ & $1(9 \%)$ & 0.63 \\
\hline Coronary disease & $3(9 \%)$ & $4(36 \%)$ & 0.028 \\
\hline Diabetes & $2(6 \%)$ & $2(18 \%)$ & 0.21 \\
\hline Rheumatism & $2(6 \%)$ & None & 0.41 \\
\hline Psoriatic arthritis & $1(3 \%)$ & $2(18 \%)$ & 0.14 \\
\hline Bechterew's disease & $1(3 \%)$ & None & 0.57 \\
\hline Hyperthyroidism & None & $1(9 \%)$ & 0.24 \\
\hline \multicolumn{4}{|l|}{ Mean values, $\pm \mathrm{SD}^{\mathrm{c}}$} \\
\hline Hemoglobin (g/dl) & $14.3 \pm 1.2$ & $14.3 \pm 1.6$ & 0.96 \\
\hline Glucose $(\mathrm{mmol} / \mathrm{l})$ & $6.8 \pm 2.3$ & $7.7 \pm 2.4^{\mathrm{a}}$ & 0.29 \\
\hline \multicolumn{4}{|l|}{ Median values, interquartile range ${ }^{\mathrm{d}}$} \\
\hline BI-20 & $20(19,20)^{\mathrm{b}}$ & $18(16,20)$ & 0.06 \\
\hline Infarct volume $\left(\mathrm{cm}^{3}\right)$ & $2(1,16.8)$ & - & - \\
\hline $\mathrm{CRP}(\mathrm{mg} / \mathrm{l})$ & $2.5(2.0,6.3)$ & $4.0(2.0,7.0)$ & 0.99 \\
\hline \multicolumn{4}{|l|}{ Median values, interquartile range ${ }^{\mathrm{d}}$} \\
\hline \multicolumn{4}{|l|}{ Cytokines } \\
\hline IL-1 ra $(\mu \mathrm{g} / \mathrm{ml})$ & $1,206(917,1,618)$ & $843(718,1,561)$ & 0.26 \\
\hline IL-8 ( $\mu \mathrm{g} / \mathrm{ml})$ & $192(122,228)$ & $267(123,367)$ & 0.11 \\
\hline IL-18 $(\mu \mathrm{g} / \mathrm{ml})$ & $1,807(1,474,2,255)$ & $1,649(1,227,2,290)$ & 0.49 \\
\hline GRO- $\alpha$ & $1,613(520,2,192)$ & $888(0,1,214)$ & $\mathbf{0 . 0 2 3}$ \\
\hline \multicolumn{4}{|c|}{ Dichotomized values ${ }^{\mathrm{e}}(\%$ detectable of total) } \\
\hline \multicolumn{4}{|l|}{ Cytokines } \\
\hline IL-1 $\beta$ & $8(24 \%)$ & $2(18 \%)$ & 0.83 \\
\hline IL-2 & $1(3 \%)$ & $1(9 \%)$ & 0.79 \\
\hline IL-4 & $8(24 \%)$ & $1(10 \%)$ & 0.65 \\
\hline IL-6 & $31(91 \%)$ & $11(100 \%)$ & 0.09 \\
\hline IL-9 & $16(47 \%)$ & $2(20 \%)$ & 0.30 \\
\hline IL-10 & $18(53 \%)$ & $6(55 \%)$ & 0.65 \\
\hline IL-12 & $20(59 \%)$ & $7(64 \%)$ & 0.78 \\
\hline $\mathrm{IFN}-\gamma$ & $8(24 \%)$ & $4(36 \%)$ & 0.56 \\
\hline TNF- $\alpha$ & $20(59 \%)$ & 7 (64\%) & 0.81 \\
\hline
\end{tabular}

Significant findings $(p<0.05)$ are marked with bold-faced types

a One missing case

b Two missing cases

c The independent sample t-test was used to compare means

d The two-tailed Mann-Whitney test was used to compare median values

e The two-tailed Mann-Whitney test was used to compare median values for the continuously values 


\section{Discussion}

Our finding of significantly elevated circulatory IL-6 in the AIS patients is consistent with the findings of numerous previous studies [7-10, 20-25]. Although IL-6 is predominantly viewed as a proinflammatory cytokine, it has been suggested that it has two roles in cerebral ischemia: (1) as an inflammatory mediator during the acute phase and (2) as a neurotrophic mediator between the subacute and prolonged phases [26].

TNF- $\alpha$ and IL- $1 \beta$ were not elevated in the AIS group, which is in accordance with two previous studies [7, 27], but conflicts with others $[15,23,28]$. Based on the findings that TNF- $\alpha$ and IL- $1 \beta$ are detectable as early as $1 \mathrm{~h}$ after the onset of ischemia [26], and IL-6 is up-regulated by IL$1 \beta$ and TNF- $\alpha$ [29], it is reasonable to assume that the levels of TNF- $\alpha$ and IL- $1 \beta$ had already peaked when we made our measurements. Our findings of elevated levels of IL-6 and IL-1ra, but not of TNF- $\alpha$ and IL- $\beta$, support earlier findings that IL- 6 suppresses the effects of TNF- $\alpha$ and IL$1 \beta$ both by inhibiting their production and by stimulating the production of their respective circulating antagonists: soluble TNF- $\alpha$ receptor and IL-1 receptor antagonist [30, 31]. Previous studies have also found elevated IL-1ra levels in stroke patients $[20,27]$. Consistent with our findings, Beamer and coworkers found that both IL-1ra and IL-6 levels are elevated in stroke patients [32].

We found only one previous study of circulating IL-12 in AIS patients [33]. Consistent with our study, they found an early increase in IL-12 serum level. Our finding of significantly elevated IL-18 levels in the AIS group is supported by two previous studies [34, 35]. These results suggest that both IL-12 and IL-18 are involved in strokeinduced inflammation. Serum levels of IFN- $\gamma$ were not elevated in the AIS group. We have not found any previous studies on circulating IFN $-\gamma$ in AIS patients.

Studies of IL-8 in AIS patients are also scarce. In accordance with the present study, two other studies found a significant elevation of plasma IL-8 in AIS patients [36, 37], while another study did not [38]. We found a significant correlation between serum IL- 8 and age in the patient group. The difference in IL- 8 between the groups remained significant after adjusting for age $(p<0.001)$. This indicates that IL- 8 may be a more prominent cytokine in older patients. It is interesting to ask whether IL-8 may contribute to that older age predicts poorer functional outcome $[39,40]$ and mortality [41] after stroke. More studies are needed to verify the role of IL-8 in older stroke patients.

We found that levels of GRO- $\alpha$ (also known as CXCL1), a proinflammatory chemokine similar to IL-8, were significantly elevated in the AIS group. We were unable to find any other study measuring circulating GRO- $\alpha$ in AIS patients; however, elevated cerebrospinal fluid levels of this cytokine in AIS patients have been noted [42]. The ability of GRO- $\alpha$ to interact with other cytokines and adhesion molecules expressed after stroke so as to potentially promote leukocyte migration into the ischemic brain has been thoroughly reviewed [42].

We found a significant elevation in IL-9 in the AIS group. To the best of our knowledge, our study is the first to have measured IL-9 in AIS patients, thus the role for IL9 in the progression of AIS is unclear. However, it has been shown that the IL-9/IL-9 receptor signaling pathway represents a novel endogenous antiapoptotic mechanism for cortical neurons [43]. It may therefore be hypothesized that IL-9 may protect against stress-induced neuronal damage.

IL-10, but not IL-4, was significantly elevated in the AIS patients. One previous study supports our findings regarding IL-4 [44]. A significant decrease in IL-10 concentration at $24 \mathrm{~h}$ followed by significant increases at 72 and $144 \mathrm{~h}$ has recently been found [45]. Elevated levels of the antiinflammatory cytokines IL-10 and IL-1ra suggest early activation of endogenous immunosuppressive mechanisms after stroke.

There have been large variations between similar studies exploring relevant confounding factors such as medication and comorbidities. To study a broader, more typical stroke population, we chose not to exclude patients who were using anti-inflammatory drugs, or those having any comorbidity, except for cancer. The significant differences between the groups remained significant (except for IL-9) after adjusting for the medication or comorbidity (except for hypertension) present in 20 patients (data not shown). Hypertension was not excluded, because if we did, only 11 patients remained in the stroke group, which is too low of a number for an appropriate statistical analysis.

No association was found between any of the studied variables and stroke lateralization in our study. Relevant research on whether the site of the lesion plays a role in regulating alterations in the immune response in stroke is limited. To the best of our knowledge, no other studies have related stroke laterality to serum levels of cytokines in AIS patients.

We found that infarct volume was significantly positively correlated with CRP levels $(r=0.47, p=0.005)$. This is expected to be of clinical relevance, as a considerable difference in median volume score was found between patients with CRP above and below the median CRP value $(2.5 \mathrm{~g} / \mathrm{l}) ; 11 \mathrm{vs.} 1 \mathrm{~cm}^{3}$, respectively. The findings of previous studies on the correlation between CRP and cerebral infarct volume are conflicting; two are in accordance with our findings [11,38], one failed to find a correlation [24], and one found a higher plasma CRP only for patients with larger infarcts [46]. We did not find any correlations between infarct volume and the levels of cytokines. Previous studies have produced conflicting 
findings also regarding IL-6 levels and infarct volume. Several have shown positive correlations between infarct volume and IL-6 level in serum or plasma [7, 9-11], while Sotgiu and coworkers found serum IL-6 levels to be significantly negatively correlated with infarct volume [14], and two other studies found no association between serum IL-6 concentration and infarct volume [8, 21].

The release of inflammatory markers and lesion progression after a stroke are time dependent. The differences between the aforementioned studies may be attributable to large variations in timings of blood sampling and measurements of infarct volume. We used a wide time window for both. There are large variations between the aforementioned studies regarding the timings of blood sampling and volumetric measurements, and reasonable explanations for the divergent findings cannot be found. Our finding that CRP was significantly positively correlated with infarct volume, whereas the IL-6 was not, may reflect that IL-6 is more sensitive to measurement timing. More studies are needed, and in particular those designed to elucidate the release of inflammatory markers in AIS and their role in the progression of cerebral tissue injury. One aim of such studies should be to clarify whether a reduction in some central inflammatory markers could be beneficial to stroke patients.

Another aspect of blood samples timing is the question of the stability of cytokines in blood. In our study, for 35 of the 45 patients, blood samples were taken within $24 \mathrm{~h}$ after stroke onset $\left(T_{24}\right), 7$ were taken $24-48 \mathrm{~h}\left(T_{24-48}\right)$ after stroke onset and finally, 3 were taken between 48 and $72 \mathrm{~h}$ ( $\left.T_{48-72}\right)$ after stroke onset. The $T_{24-48}(n=7)$ and $T_{48-72}$ $(n=3)$ groups were considered too small to allow for detailed statistical analysis. However, we found the same significant differences between the stroke patients and controls analyzing the $T_{24}$ sample alone, the $T_{24}+T_{24-48}$ sample, and finally, as presented in the paper, the $T_{24}+T_{24-48}+T_{48-72}$ sample. Thus significant elevated cytokine levels were found, in accordance with earlier studies as discussed above, also in this "time-broad-sample". This indicates that elevated cytokine levels may last longer than earlier supposed. This is supported by several studies; serum levels of IL-6 has been found elevated until 90 days after the stroke [8, 10, 21], and IL- 8 has been found elevated in plasma during the first week after ischemic stroke [47]. In our opinion, our results are strengthened by the fact that including these late samples did not affect the significant finding.

It is furthermore likely that the distribution of stroke subtypes influences the differential findings discussed. For CRP, this is supported by the finding of higher plasma CRP only in patients with larger infarcts [46]. Regarding IL-6, CEI subtype has been found to exhibit significantly higher plasma levels of IL-6 (and TNF- $\alpha$ and IL1- $\beta$ ), whereas
LAC subtype exhibited significantly lower plasma levels of these cytokines [15]. In our study, the numbers of patients in the different subtype groups were low, and the distribution was skewed. Some of the TOAST groups were too small to allow for more detailed statistical analysis, which is also a limitation of our study. However, we did find that the serum level of GRO- $\alpha$ was significantly higher in patients with radiologically confirmed infarctions (pooled subtypes CEI, LAAS, and LAC) than in patients without (subtype UDE), where the latter had nearly normal levels of GRO- $\alpha$. These findings are novel and may indicate that GRO- $\alpha$ may be the only cytokine measured that is specific for strokes of known etiology. This aspect of GRO- $\alpha$ is interesting and should be studied further in aim to accomplish more knowledge about the pathophysiological mechanisms in stroke of known etiology distinct to cryptogenic stroke.

The mean age was significantly higher in the group of patients without radiologically confirmed infarctions as compared to those with (74 vs. 56 years, $p=0.037$ ). A higher age among patients with UDE was also noted in a population-based study on 531 stroke patients [48].

Another limitation of this study is that stroke severity was not measured by using i.e., National Institutes of Health Stroke Scale (NIHSS) or the Scandinavian Stroke Scale. The BI-20 score was measured in the acute phase to assess early functional disability, and was found to be significantly negatively correlated with levels of IL-2, IL-6, IL-12, and IFN- $\gamma$. An association between IL- 6 and IL-12 and acute clinical outcome has also been noted by others, using the NIHSS $[25,49]$ and the BI-20 [33], respectively.

\section{Conclusions}

This is the first study to examine the serum levels of 13 cytokines in a single AIS population using one methodology; eight were found to be elevated. The findings of elevated levels of IL-9 and GRO- $\alpha$ in AIS patients are novel. Our study supports the assertion that inflammatory signaling molecules are of importance in AIS; an association, assumed to be of clinical relevance, was found between infarct volume and CRP level. Patients with radiologically confirmed infarctions had significantly elevated GRO- $\alpha$, indicating that this cytokine may be the only one specific for strokes of known etiology.

Acknowledgments The presented work stems from the research project "Poststroke Fatigue", for which Dr. Hesook Suzie Kim is the project director and Drs. Grethe Eilertsen, Anners Lerdal, and Heidi Ormstad are the principal researchers. The project is funded by the Research Council of Norway for the period from 2007 to 2010 (project no. 176503/V10). The authors are indebted to various staff members of Buskerud Hospital, Drammen, for recruiting the patients, 
in particular to Eli Fossan Rasmussen. We thank Ragnhild Grøndahl and Tove Alstad for expert assistance with the blood samples. The research assistant in the project, Gunn Pedersen, is thanked for essential contributions to the recruitment procedure and data collection. We also thank Dr. Hans Erik Heier and Menaka S. Andersen at The Bloodbank, Oslo University Hospital, Ullevål, Oslo, for facilitating the collection of material from normal controls. Finally, we thank Dr. Arnljot Tveit for constructive comments to earlier versions of the manuscript. The study was approved by the Regional Committee For Medical Research Ethics in Norway and have therefore been performed in accordance with the ethical standards laid down in the 1964 Declaration of Helsinki. Informed consent was obtained from all patients prior to their inclusion in the study.

Conflict of interest The authors declare no conflict of interest.

Open Access This article is distributed under the terms of the Creative Commons Attribution Noncommercial License which permits any noncommercial use, distribution, and reproduction in any medium, provided the original author(s) and source are credited.

\section{References}

1. McColl BW, Allan SM, Rothwell NJ (2009) Systemic infection, inflammation and acute ischemic stroke. Neuroscience 158:10491061

2. Wang Q, Tang XN, Yenari MA (2007) The inflammatory response in stroke. J Neuroimmunol 184:53-68

3. Sairanen T, Carpen O, Karjalainen-Lindsberg ML, Paetau A, Turpeinen U, Kaste M, Lindsberg PJ (2001) Evolution of cerebral tumor necrosis factor-alpha production during human ischemic stroke. Stroke 32:1750-1758

4. Feuerstein GZ, Wang X, Barone FC (1998) The role of cytokines in the neuropathology of stroke and neurotrauma. Neuroimmunomodulation 5:143-159

5. Stoll G, Jander S, Schroeter M (1998) Inflammation and glial responses in ischemic brain lesions. Prog Neurobiol 56:149-171

6. Kriz J, Lalancette-Hébert M (2009) Inflammation, plasticity and real-time imaging after cerebral ischemia. Acta Neuropathol 117:497-509

7. Fassbender K, Rossol S, Kammer T, Daffertshofer M, Wirth S, Dollman M, Hennerici M (1994) Proinflammatory cytokines in serum of patients with acute cerebral ischemia: kinetics of secretion and relation to the extent of brain damage and outcome of disease. J Neurol Sci 122:135-139

8. Tarkowski E, Rosengren L, Blomstrand C, Wikkelsö C, Jensen C, Ekholm S, Tarkowski A (1995) Early intrathecal production of interleukin-6 predicts the size of brain lesion in stroke. Stroke 26:1393-1398

9. Vila N, Castillo J, Dávalos A, Chamorro A (2000) Proinflammatory cytokines and early neurological worsening in ischemic stroke. Stroke 31:2325-2329

10. Acalovschi D, Wiest T, Hartmann M, Farahmi M, Mansmann U, Auffarth GU, Grau AJ, Green FR, Grond-Ginsbach C, Schwaninger M (2003) Multiple levels of regulation of the interleukin-6 system in stroke. Stroke 34:1864-1870

11. Smith CJ, Emsley HC, Gavin CM, Georgiou RF, Vail A, Barberan EM, del Zoppo GJ, Hallenbeck JM, Rothwell NJ, Hopkins SJ, Tyrrell PJ (2004) Peak plasma interleukin-6 and other peripheral markers of inflammation in the first week of ischaemic stroke correlate with brain infarct volume, stroke severity and long-term outcome. BMC Neurol 4:2
12. Di Napoli M, Schwaninger M, Cappelli R, Ceccarelli E, Di Gianfilippo G, Donati C, Emsley HC, Forconi S, Hopkins SJ, Masotti L, Muir KW, Paciucci A, Papa F, Roncacci S, Sander D, Sander K, Smith CJ, Stefanini A, Weber D (2005) Evaluation of $\mathrm{C}$-reactive protein measurement for assessing the risk and prognosis in ischemic stroke: a statement for Health Care Professionals from the CRP Pooling Project Members. Stroke 36:13161329

13. Smith CJ, Emsley HCA, Vail A, Georgiou RF, Rothwell NJ, Tyrrell PJ, Hopkins SJ (2006) Variability of the systemic acute phase response after ischemic stroke. J Neurol Sci 251:77-81

14. Sotgiu S, Zanda B, Marchetti B, Fois ML, Arru G, Pes GM, Salaris FS, Arru A, Pirisi A, Rosati G (2006) Inflammatory biomarkers in blood of patients with acute brain ischemia. Eur $\mathrm{J}$ Neurol 13:505-513

15. Licata G, Tuttolomondo A, Di Raimondo D, Corrao S, Di Sciacca R, Pinto A (2009) Immuno-inflammatory activation in acute cardio-embolic strokes in comparison with other subtypes of ischaemic stroke. Thromb Haemost 101:929-937

16. Lerdal A, Bakken LN, Rasmussen EF, Beiermann C, Ryen S, Pynten S, Drefvelin AS, Dahl AM, Rognstad G, Finset A, Lee KA, Kim HS (2011) Physical impairment, depressive symptoms and pre-stroke fatigue are related to fatigue in the acute phase after stroke. Disabil Rehabil 33:334-342

17. Adams HP Jr, Bendixen BH, Kappelle LJ, Biller J, Love BB, Gordon DL (1993) Classification of subtype of acute ischemic stroke. Definitions for use in a multicenter clinical trial. TOAST. Trial of Org 10172 in Acute Stroke Treatment. Stroke 24:35-41

18. Collin C, Wade DT, Davies S, Horne V (1988) The Barthel ADL Index: a reliability study. Int Disabil Stud 10:61-63

19. Wolfe CDA, Taub NA, Woodrow EJ, Burney PGJ (1991) Assessment of scales of disability and handicap for stroke patients. Stroke 22:1242-1244

20. Beamer NB, Coull BM, Clark WM, Hazel JS, Silberger JR (1995) Interleukin-6 and interleukin-1 receptor antagonist in acute stroke. Ann Neurol 37:800-804

21. Ferrarese C, Mascarucci P, Zoia C, Cavarretta R, Frigo M, Begni B, Sarinella F, Frattola L, De Simoni MG (1999) Increased cytokine release from peripheral blood cells after acute stroke. J Cereb Blood Flow Metab 19:1004-1009

22. Emsley HC, Smith CJ, Gavin CM, Georgiou RF, Vail A, Barberan EM, Hallenbeck JM, del Zoppo GJ, Rothwell NJ, Tyrrell PJ, Hopkins SJ (2003) An early and sustained peripheral inflammatory response in acute ischaemic stroke: relationships with infection and atherosclerosis. J Neuroimmunol 139:93-101

23. Mazzotta G, Sarchielli P, Caso V, Paciaroni M, Floridi A, Floridi A, Gallai V (2004) Different cytokine levels in thrombolysis patients as predictors for clinical outcome. Eur $\mathrm{J}$ Neurol 11:377-381

24. Waje-Andreassen U, Krakenes J, Ulvestad E, Thomassen L, Myhr KM, Aarseth J, Vedeler CA (2005) IL-6: an early marker for outcome in acute ischemic stroke. Acta Neurol Scand 111:360-365

25. Basic Kes V, Simundic AM, Nikolac N, Topic E, Demarin V (2008) Pro-inflammatory and anti-inflammatory cytokines in acute ischemic stroke and their relation to early neurological deficit and stroke outcome. Clin Biochem 41:1330-1334

26. Suzuki S, Tanaka K, Suzuki N (2009) Ambivalent aspects of interleukin-6 in cerebral ischemia: inflammatory versus neurotrophic aspects. J Cereb Blood Flow Metab 29:464-479

27. Emsley HCA, Smith C, Gavin CM, Georgiou RF, Vail A, Barberan EM, Illingworth $\mathrm{K}$, Scarth S, Wickramasinghe V, Hoadley ME, Rothwell NJ, Tyrrell PJ, Hopkins SJ (2007) Clinical outcome following acute ischaemic stroke relates to both activation and autoregulatory inhibition of cytokine production. BMC Neurology 7:5 
28. Zaremba J, Skrobanski P, Losy J (2001) Tumour necrosis factoralpha is increased in the cerebrospinal fluid and serum of ischaemic stroke patients and correlates with the volume of evolving brain infarct. Biomed Pharmacother 55:258-263

29. Shalaby MR, Waage A, Aarden L, Espevik T (1989) Endotoxin, tumor necrosis factor- $\alpha$ and interleukin 1 induce interleukin 6 production in vivo. Clin Immunol Immunopathol 53:488-498

30. Hirano $T$ (1992) The biology of interleukin-6. Chem Immunol 51:153-180

31. Tilg H, Trehu E, Atkins MB (1994) Interleukin-6 (IL-6) as an anti-inflammatory cytokine: induction of circulating IL-1 receptor antagonist and soluble tumor necrosis factor receptor p55. Blood 83:113-118

32. Beamer NB, Coull BM, Clark WM, Briley DP, Wynn M, Sexton G (1998) Persistent inflammatory response in stroke survivors. Neurology 50:1722-1728

33. Zaremba J, Losy J (2006) Interleukin-12 in acute ischemic stroke patients. Folia Neuropathol 44:59-66

34. Zaremba J, Losy J (2003) Interleukin-18 in acute ischemic stroke patients. Neurol Sci 24:117-124

35. Yuen CM, Chiu CA, Chang LT, Liou CW, Lu CH, Youssef AA, Yip HK (2007) Level and value of interleukin-18 after acute ischemic stroke. Circ J 71:1691-1696

36. Kostulas N, Pelidou SH, Kivisakk P, Kostulas V, Link H (1999) Increased IL-1 $\beta$, IL-8, and IL-17 mRNA Expression in blood mononuclear cells observed in a prospective ischemic stroke study. Stroke 30:2174-2179

37. Al-Bahrani A, Taha S, Shaath H, Bakhiet M (2007) TNF- $\alpha$ and IL- 8 in acute stroke and the modulation of these cytokines by antiplatelet agents. Curr Neurovasc Res 4:31-37

38. Pedersen ED, Waje-Andreassen U, Vedeler CA, Aamodt G, Mollnes TE (2004) Systemic complement activation following human acute ischaemic stroke. Clin Exp Immunol 137:117-122

39. Kelly-Hayes M, Beiser A, Kase CS, Scaramucci A, D'Agostino RB, Wolf PA (2003) The influence of gender and age on disability following ischemic stroke: the Framingham study. J Stroke Cerebrovasc Dis 12:119-126
40. Bhalla A, Grieve R, Tilling K, Rudd AG, Wolfe CD (2004) Older stroke patients in Europe: stroke care and determinants of outcome. Age Ageing 33:618-624

41. Koton S, Tanne D, Green MS, Bornstein NM (2010) Mortality and predictors of death 1 month and 3 years after first-ever ischemic stroke: data from the first national acute stroke Israeli survey (NASIS 2004). Neuroepidemiology 34:90-96

42. Losy J, Zaremba J, Skrobañski P (2005) CXCL1 (GRO-alpha) chemokine in acute ischaemic stroke patients. Folia Neuropathol 43:97-102

43. Fontaine RH, Cases O, Lelièvre V, Mesplès B, Renauld JC, Loron G, Degos V, Dournaud P, Baud O, Gressens P (2008) (2008). IL-9/ IL-9 receptor signaling selectively protects cortical neurons against developmental apoptosis. Cell Death Differ 15:1542-1552

44. Vila N, Castillo J, Dávalos A, Esteve A, Planas AM, Chamorro Á (2003) Levels of anti-inflammatory cytokines and neurological worsening in acute ischemic stroke. Stroke 34:671-675

45. Nayak AR, Kashyap RS, Purohit HJ, Kabra D, Taori GM, Daginawala HF (2009) Evaluation of the inflammatory response in sera from acute ischemic stroke patients by measurement of IL-2 and IL-10. Inflamm Res 58:687-691

46. Marquardt L, Ruf A, Mansmann U, Winter R, Buggle F, Kallenberg K, Grau AJ (2005) Inflammatory response after acute ischemic stroke. J Neurol Sci 236:65-71

47. Kostulas N, Kivisakk P, Huang Y, Matusevicius D, Kostulas V, Link H (1998) Ischemic stroke is associated with a systemic increase of blood mononuclear cells expressing interleukin-8 mRNA. Stroke 29:462-466

48. Kolominsky-Rabas PL, Weber M, Gefeller O, Neundoerfer B, Heuschmann PU (2001) Epidemiology of ischemic stroke subtypes according to TOAST criteria: incidence, recurrence, and long-term survival in ischemic stroke subtypes: a populationbased study. Stroke 32:2735-2740

49. Shenhar-Tsarfaty S, Assayag EB, Bova I, Shopin L, Berliner S, Shapira I, Bornstein NM (2008) Early signaling of inflammation in acute ischemic stroke: clinical and rheological implications. Thromb Res 122:167-173 